\title{
Continental hydrologic assessment using the 1 second (30m) resolution Shuttle Radar Topographic Mission DEM of Australia
}

\author{
$\underline{\text { T.I. Dowling }}{ }^{\text {a }}$, M. Brooks ${ }^{\text {b }}$ and A. M. Read ${ }^{\text {a }}$ \\ ${ }^{a}$ CSIRO, Land and Water, Australian Capital Territory \\ ${ }^{b}$ Bureau of Meteorology, Australian Capital Territory \\ Email: trevor.dowling@,csiro.au
}

\begin{abstract}
The release of the Shuttle Radar Topographic Mission (SRTM) digital elevation data for Australia in 2005 created the opportunity for a substantial step forward in digital elevation models (DEMs) for the continent. Subsequent processing of the data by CSIRO has resulted in the first 1 second $(\sim 30 \mathrm{~m})$ resolution hydrological DEM covering the entire continent. The completed products include: the DSM, a cleaned digital surface model with stripes removed and voids filled but with noise and offsets due to vegetation still present; the DEM, a bare-earth digital elevation model with vegetation offsets removed but still containing substantial noise; and the DEM-S, an adaptively smoothed bare-earth model with much reduced noise, especially in flatter areas.
\end{abstract}

The final product, the DEM-H, is a drainage enforced (hydrological) elevation model that captures channel networks and is necessary because residual vegetation artefacts are most significant around streams in flat landscapes. DEM-H combines DEM-S and drainage from AusHydro, a 1:250,000 national stream dataset.

Since 1975 the Australian Water Resources Council (AWRC) Drainage Divisions have been used for regional scale water management and planning. In 2010 a revised set of Draft Australian Water Resources Assessment (AWRA) regions were derived by the Bureau of Meteorology based on the GEODATA 9 second $(\sim 250 \mathrm{~m})$ DEM. This paper explores the potential of DEM-H for use in improving the definition of drainage divisions by examining differences between catchments derived from DEM-H with the AWRC and draft AWRA catchments.

Comparisons were made by overlaying polygons derived from each data source and checking the differences against scanned 1:250,000 topographic maps, satellite imagery and the 1 second SRTM DEM (vegetation removed). In most cases visual trends in the dense but noisy SRTM data were sufficient to determine which boundary was most correct. Confidence in SRTM data was assessed locally by profiling the DEMs through known 1:250,000 mapped spot height locations.

The results show a considerable overall improvement in catchment definition from the AWRC and AWRA sources, commensurate with the increase in resolution. The Yarra Yarra Creek catchment in Western Australia is a typical example where catchment boundaries differed significantly in subtle terrain. The boundaries vary by about $20 \mathrm{~km}$ in several places. The AWRC catchments are clearly the most limited being generalised from 1:250,000 paper maps and sometimes conforming to management rather than topographic principles. The AWRA catchments are generally an improvement however errors occur due to the interpolation of sparse input data and a resolution where small but significant features were missed in the space of just a few 250m cells. While DEM-H resolves most differences between AWRC and AWRA boundaries some ambiguities still remain in flat areas where subtle relief approaches the noise level in the data or residual vegetation artefacts persist. It is unfortunate that the release of the AWRA drainage boundaries could not wait for the analysis of the 1 second DEM and a revision is likely in the near future.

DEM-H represents a significant step forward in deriving continental scale terrain attributes and checking existing DEMs and derived hydrologic features.

Keywords: SRTM 1 second DEM, continental hydrology 
Dowling et al., Continental hydrologic assessment using the 1 second (30m) SRTM DEM of Australia.

\section{INTRODUCTION}

The need for high quality drainage networks and contributing areas has been given impetus in Australia by recent requirements for more accurate assessment, accounting and reporting of water resources by the Bureau of Meteorology (BoM, 2011a). The accepted framework for continental scale water resource assessment since 1975 has been the Australian Water Resources Council drainage divisions (AWRC, 1976). The data sources and methods used for delineating the 244 basins in 12 drainage divisions were not well documented, although they included 197 basins from the original review (AWRC, 1965). It is likely they were derived by State agencies based largely on available 1:250,000 topographic mapping for much of the continent. The boundary detail is often generalized in flat landscapes where distances between contours can reach tens of kilometres and some boundaries appear to be based more on administrative boundaries than topographic catchments. There have been revisions since 1976 but the boundaries have remained essentially the same.

Hutchinson and Dowling (1991) showed the potential for using DEMs for continental hydrological assessment by comparing $1 / 20^{\text {th }}(5 \mathrm{~km})$ and $1 / 40^{\text {th }}$ degree $(2.5 \mathrm{~km})$ resolution continental DEMs of Australia. They noted that drainage divisions afforded by the analysis of the arid western plateau region were markedly different from those presented by the AWRC (1976) and the differences were supported both by currently available topographic maps and by analyses of palaeodrainage systems by van de Graaff et al. (1977). Hutchinson and Dowling (1991) concluded that the $1 / 40^{\text {th }}$ degree DEM may be of use in geomorphological studies as it added strong support to the paleodrainage analysis of van de Graaff et al. (1977).

Following the $1 / 40^{\text {th }}$ degree DEM, and building on the same data and software, 3 versions of the GEODATA 9 second (250m) continental DEM have been released from 1996 to 2008 (Geoscience Australia, 2008). The latter of these was used in a recent initiative of the Bureau of Meteorology, called the Australian Hydrological Geospatial Fabric (Geofabric) project, that defines the fundamental data structures and layers for continental water assessment and accounting (BoM, 2010). This project provided the opportunity to revise the AWRC drainage divisions with more detail and confidence. The AWRA reporting regions are comprised of AWRA Drainage Divisions and underlying finer-scale AWRA River Regions (BoM, 2011b).

The release of the Shuttle Radar Topographic Mission (SRTM) digital elevation data for Australia in 2005 created the opportunity for a substantial step forward in digital elevation models (DEMs) for the continent. Subsequent processing of the data by CSIRO has resulted in the first 1 second $(\sim 30 \mathrm{~m})$ resolution hydrological DEM covering the entire continent. The completed products include: the DSM, a cleaned digital surface model with stripes removed and voids filled but with noise and offsets due to vegetation still present; the DEM, a bare-earth digital elevation model with vegetation offsets removed but still containing substantial noise; and the DEM-S, an adaptively smoothed bare-earth model with much reduced noise, especially in flatter areas.

The final product, the DEM-H, is a drainage enforced (hydrological) elevation model that captures channel networks and is necessary because residual vegetation artefacts are most significant around streams in flat landscapes. DEM-H combines DEM-S and drainage from AusHydro, a 1:250,000 national stream dataset (Geocience Australia, 2009). The greatest obstacle was the order of magnitude mismatch in resolution between datasets. A significant part of the project involved developing methods to use the stream data in flat areas where they were most needed and exclude them from steeper areas and derive new ones where the SRTM data was generally better for deriving streams directly.

The 1 second (30m) Shuttle Radar Topographic Mission (SRTM) derived DSM and DEMs were released in stages from 2009 to 2011. They were strictly licensed for Government use only, although any derived products could be distributed freely (Geoscience Australia and CSIRO Land and Water, 2011). The SRTM data is a dense but noisy elevation data set that provides consistent detailed topography over the entire continent, revealing subtle landforms that have never been captured before and creating new opportunities for high resolution continental terrain modelling.

One such application is a high resolution revision of the continental drainage basins. Unfortunately a number of factors impede that pursuit:

- each continental DEM is approximately $40 \mathrm{~GB}$

- the dataset is maintained in $1 \times 1$ degree tiles for manageability

- 32 bit software has a $2 \mathrm{~GB}$ address limit (i.e. DEM size)

- 64 bit terrain analysis software, or programs that can manage tiled data, for terrain analysis and connected flow algorithms in particular, are still in an immature state and being developed. 
In the interim, given an immediate need for revised boundaries, the 1 second data can be used in manageable pieces to check inconsistencies between the existing versions of drainage basins and help determine the most correct. Overlaying the proposed AWRA regions on the AWRC basins (Figure 1) highlights the differences and thus the potential changes to the long accepted drainage basin boundaries of Australia. The objective of this paper is to explore the potential contribution of the 1 second DEM to continental hydrological assessment. More specifically it focuses on the usefulness of the 1 second SRTM derived surfaces for validating the AWRA boundaries.

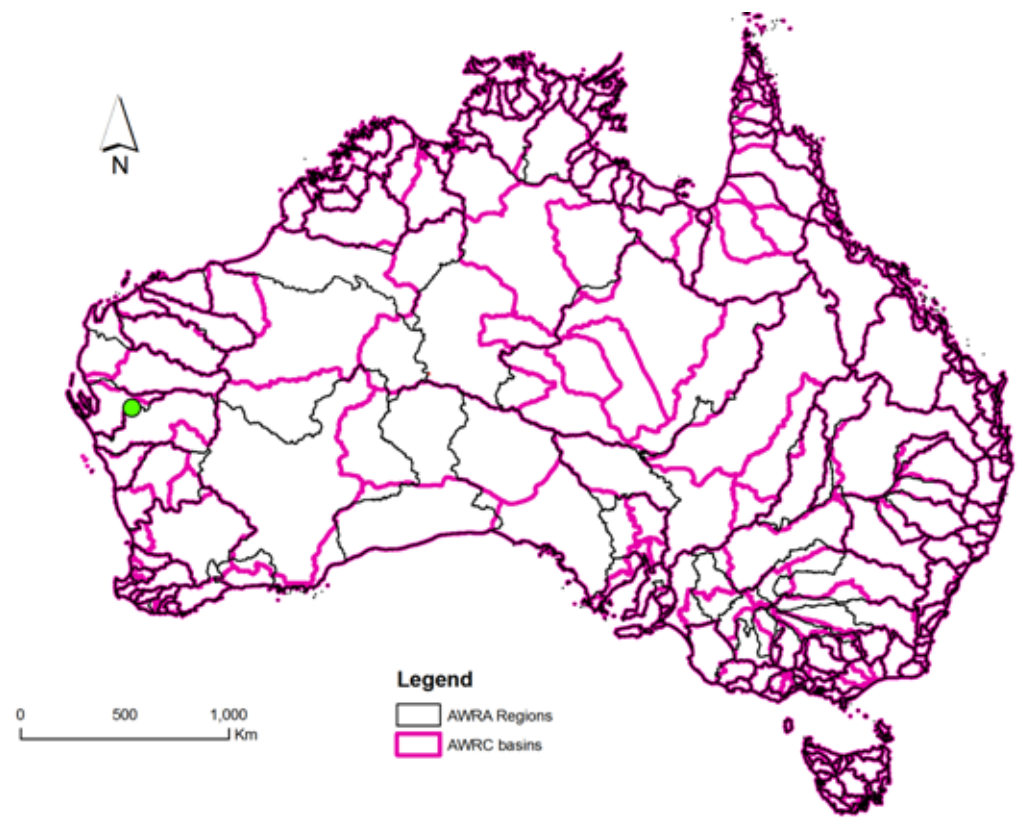

Figure 1. Comparison of AWRC Basin boundaries (purple) and draft AWRA boundaries (black) showing major differences, although many other significant differences can't be seen at this scale. The study area is located at the green dot in central-west Western Australia.

\section{BASIN DEFINITIONS}

AWRC boundaries have been available digitally for over a decade and were essentially derived from topographic maps. They are generally reasonable in hilly areas but have very smooth boundaries in flat areas where contours are very sparse and there is a paucity of other ancillary information that could help define catchments.

AWRA river regions (BoM, 2011) were derived from version 3 of the GEODATA 9 second DEM (Geoscience Australia, 2009; Stein et al., 2011). This DEM was interpolated using ANUDEM, however the input data mostly consisted of relatively sparse 1:250k data including spot heights, selected contour points, streams and other mineral survey data. Processing of this DEM for integration into the Geofabric included substantial checking and correcting of distributaries with multiple flow directions. In addition Pfafstetter codes (Verdin, 1999) were derived enabling a hierarchical labelling system for basins where levels of basins could be relatively easily navigated and reassembled. The AWRA regions were derived by selecting a Pfafstetter level that produced drainage divisions approximating those of the AWRC. Anomalies were checked by available means and, where appropriate, additional Pfafstetter coded basins were added or excluded to more closely match the AWRC while preserving the integrity of 9 second DEM flow directions (BoM, 2011).

The SRTM derived catchments were calculated from the hydrologically corrected 1 second (30m) Digital Elevation Model of Australia called DEM-H (Dowling et al., in prep). The processing of this DEM, while producing connected drainage networks, resulted in significant smoothing of the input data. When analysing the causes for differences between AWRC and AWRA catchment boundaries, two less-smoothed versions of the SRTM-derived DEM were inspected. The first was the DSM (Read et al., in prep) consisting of original data after it had been destriped of sensor induced artefacts and void filled; the second was an adaptively smoothed version of the DEM produced after estimated tree heights were removed from the DSM. This smoothed DEM-S (Gallant, 2011) was the primary input to DEM-H. 
Dowling et al., Continental hydrologic assessment using the 1 second (30m) SRTM DEM of Australia.

In order to derive 1 second catchment boundaries DEM-H was clipped or merged to an appropriate size, sinks were filled in ArcInfo GRID then flowdirections and flowaccumulations and watersheds calculated.

Yarra Yarra Ck, in central WA $(116.0 \mathrm{E}, 26.0 \mathrm{~S})$ was selected as a representative example to test the reliability of SRTM in subtle terrain and in defining catchments in uncoordinated drainage networks. The area is defined by the westward flowing Wooramel River in the north and the Murchison River to the South. Yarra Yarra Creek flows west then south toward the Murchison River but terminates in a system of salt lakes, an expression of a paleoriver where, because of the arid climate, it has rarely acted like a flowing river for many years (van de Graaff et al., 1977).

This area was initially identified because the AWRA boundaries disagreed with both the AWRC and DEMH. The inclusion of Yarra Yarra Creek in the AWRA regions was a deliberate choice based on evidence (topo maps and remote sensing) that showed a flood breakout from the Wooramel River linked with Yarra Yarra Creek which then flowed into a salt lake system. This system appears as a significant sink in the 9 second DEM.

Comparisons in this study were essentially visual with the aid of some useful tools and information, e,g, multiple grid profile software and ancillary information including raster topographic maps, satellite imagery and satellite-based flood mapping.

\section{RESULTS}

Figure 1 illustrates the large discrepancies between the AWRC and AWRA basin definitions. The Yarra Yarra Creek example marked by the green dot is comparatively small but no less significant in terms of resolving differences in subtle landscapes. Figure 2 shows the Yarra Yarra Creek catchment with AWRC, AWRA and DEM-H catchments overlain. The Wooramel River to the north is prominent and Yarra Yarra valley, or palaeoriver, is clearly draining south. Some of the salt lakes are visible in the DEM-H where the AWRA boundary crosses the valley. The northern extent of the valley is ill defined between the relatively recently uplifted range to the west and what appears to be a relict alluvial fan sloping up to the northeast, into which the Wooramel River has incised. The AWRC and DEM-H boundaries are mostly in good agreement.

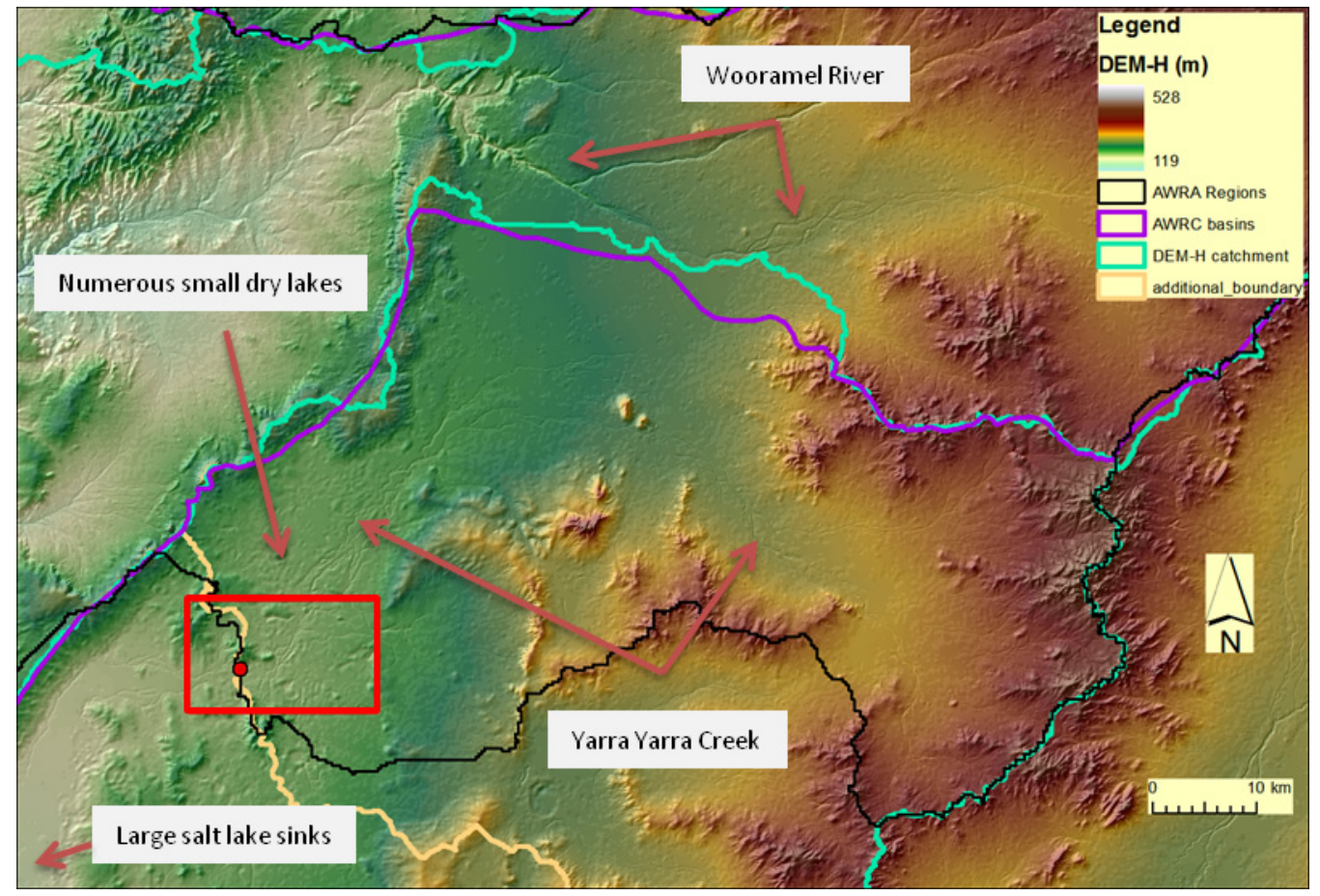

Figure 2. The Yarra Yarra Creek catchment showing detail in the 1 second DEM-H and the differences between AWRC boundaries (purple), AWRA (black) and 1 second SRTM-derived (green). The additional orange DEM-H boundary from the pour point on the AWRA catchment shows significant departure from the AWRA boundary. The red rectangle depicts the areas shown in figures 3 and 4 . 
Dowling et al., Continental hydrologic assessment using the 1 second (30m) SRTM DEM of Australia.

The profiles in Figure 3 show that the sink at point $\mathrm{C}$ in the 9 second DEM (black line in profile) has an elevation of $265 \mathrm{~m}$ while the pour point saddle is $279 \mathrm{~m}$ suggesting that the surface interpolation is being driven by the higher elevations to the north and south.

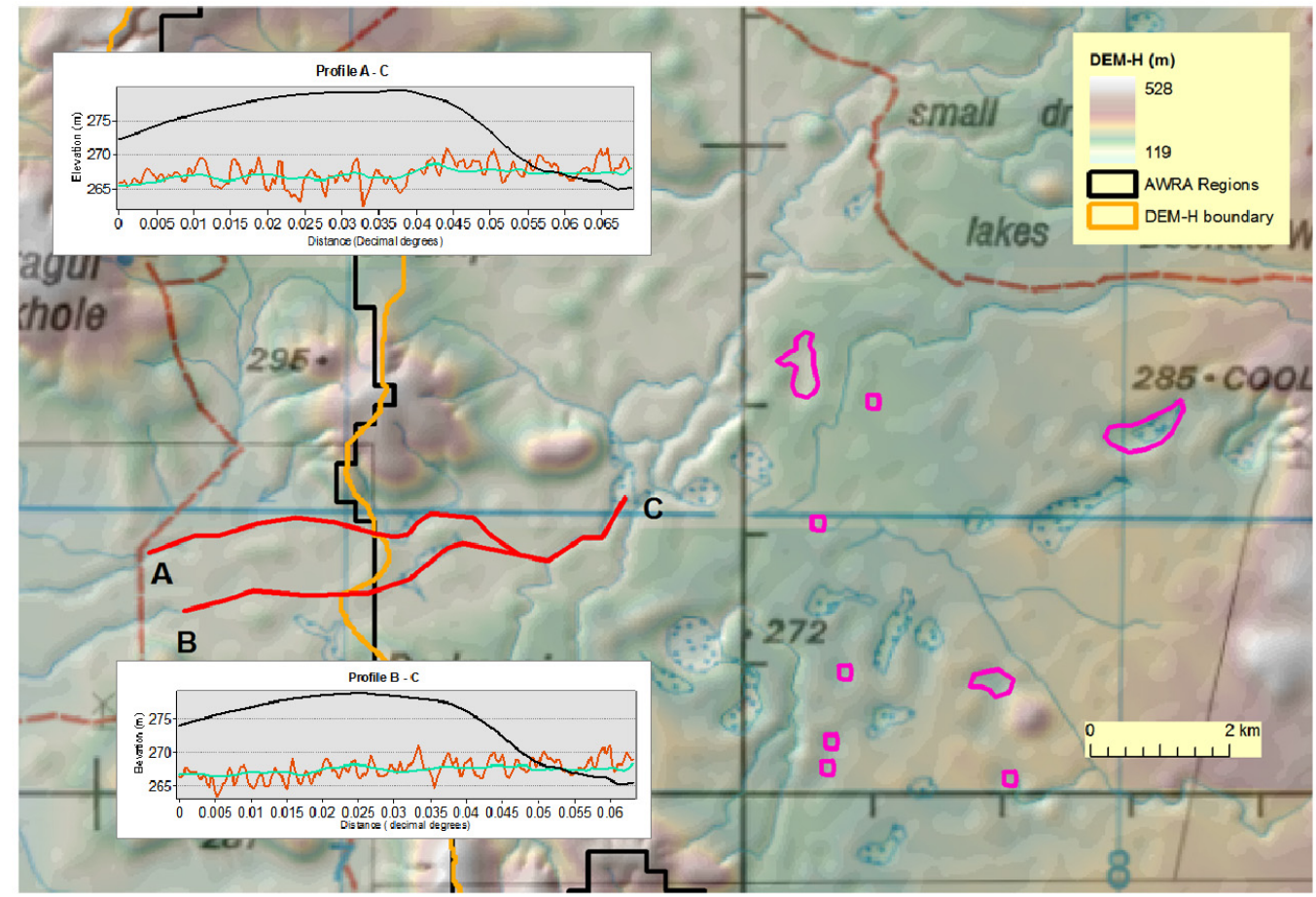

Figure 3. Yarra Yarra Creek where it appears to terminate in salt lakes showing detail from the 1:250,000 topographic map sheet. Profiles A-C and B-C show the 9 second DEM (black) and 1 second SRTM-derived DEM-H (green) and the 1 second DSM (orange). The 9 second DEM exaggerates the sink while the 1 sec data indicates a downhill trend commensurate with a 'chain of ponds' paleochannel as described by van de Graaff et al. (1977). Purple polygons denote additional lakes digitised from satellite imagery.

In contrast DEM-H (green) reveals a consistent downward trending surface with a saddle elevation of only $269 \mathrm{~m}$ retaining a sink of $267 \mathrm{~m}$. The DSM (orange) is the noisiest of the SRTM data and has a saddle at $271 \mathrm{~m}$ with the sink at $265 \mathrm{~m}$.

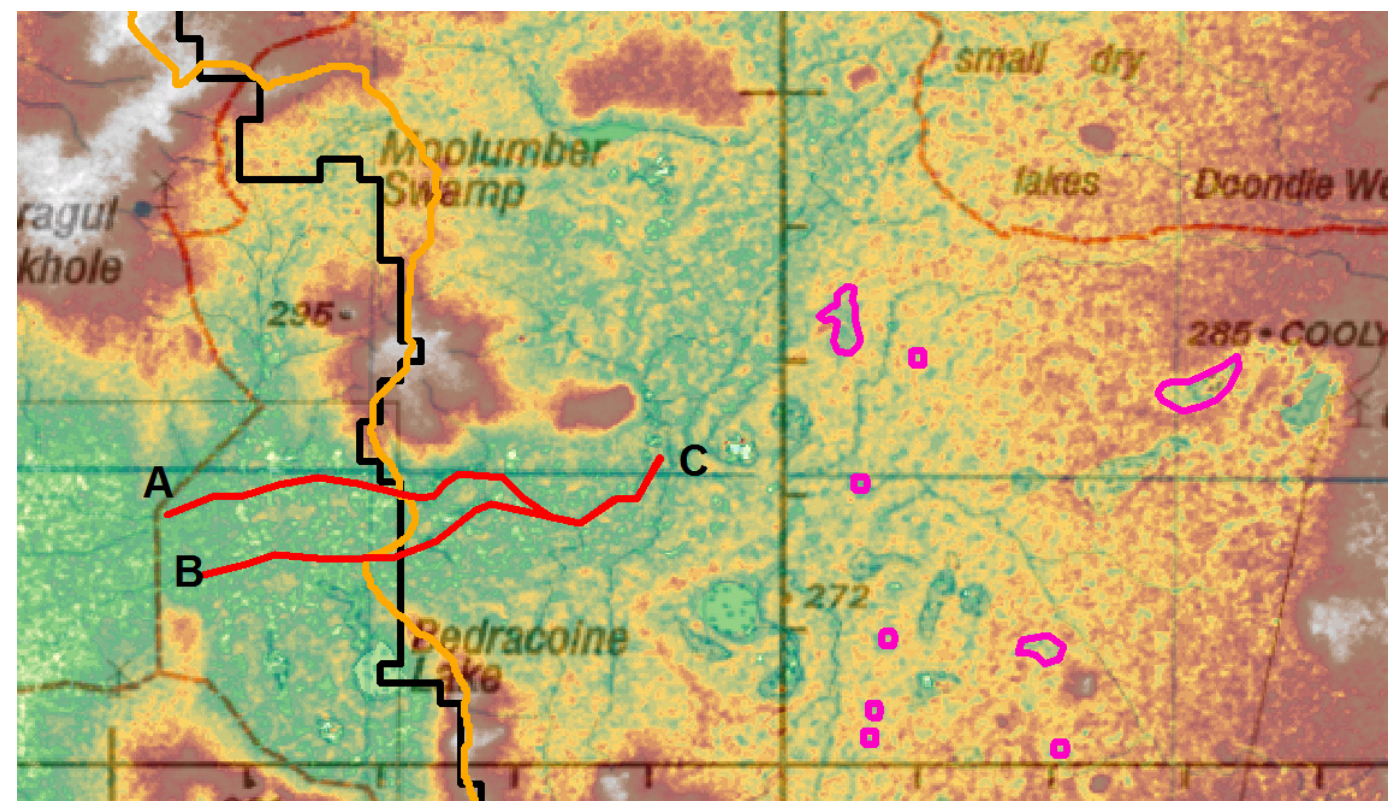

Figure 4. Yarra Yarra Creek where it appears to terminate in salt lakes showing detail in the 1 second DSM showing profile locations used in figure 3. The depiction of additional unmapped salt lakes digitized from satellite imagery

(purple) attests to the level of detail and quality of the SRTM data which is similar for the whole continent. 
Dowling et al., Continental hydrologic assessment using the 1 second (30m) SRTM DEM of Australia.

A good indication of SRTM quality is the representation of all of the lakes that appear on the published map together with more that were not mapped but are clearly visible in satellite imagery. In addition, profiles sampled through spot heights on the 1:250,000 topographic map were consistent with other error estimates for the SRTM data, having a positive offset of about $2 \mathrm{~m}$. The erroneously high elevations in the 9 second DEM are due to the influence of spot heights at local high points and the absence of a streamline enforcing the hydrological connection through the narrow gap visible in the SRTM data. This height error results in the misplaced catchment boundary seen in Figure 2.

\section{DISCUSSION}

The 1 second SRTM data adds elevation detail not previously available for much of Australia, i.e. the less populated areas. For these areas there was very little coverage until the release of the continental 9 second DEM. The main limitation with this DEM is the sparse source data in flat areas where the distances between contours can be many kilometres and generally limited information in the gaps. This lack of information leads to errors such as those shown in figures 3 and 4.

Although the SRTM is noted for being dense noisy data with potentially large errors it has been found to be very reliable with errors generally around $2 \mathrm{~m}$ (Read et al., in prep). This is generally the same for DEM-H except in some circumstances where tens of metres have been removed from mountains on predominantly smooth tiles because of the adaptive smoothing algorithm used. The most significant errors, as large as $20 \mathrm{~m}$, tend to occur where vegetation and other non-ground radar reflective objects have not been removed. These tend to be relatively local and less likely to affect catchments.

The level of detail present in the SRTM data has provided the opportunity to add to geomorphic interpretations. Rather than being an outlet for the Yarra Yarra $\mathrm{Ck}$ the northwest boundary appears to be part of a large alluvial fan built up by the Wooramel $\mathrm{R}$ in the north which has about three times the contributing area. As the Wooramel has incised through the sediments capturing more of the fan it has resulted in the catchment boundary very close to the river. Given the size of the Yarra Yarra valley the question emerges whether at some stage in the development of the fan the Wooramel River could have flowed into Yarra Yarra Creek.

The inclusion of Yarra Yarra Creek in the AWRA Wooramel river basin was a deliberate decision based on the supporting evidence of a distributary from the Wooramel linking to Yarra Yarra which then terminates in a large sink as defined by the 9 second DEM. Having multi-flow directions for distributaries causes the pfafstetter coding system to include areas that are linked upstream and downstream while the D8 flowdirections used for the 1 second analysis determines that the link belongs to the Yarra Yarra creek into which it flows.

The analysis using the detail inherent in DEM-H brings into question whether the sink is in fact significant. In support of DEM-H and the AWRC, satellite imagery of a February 2011 flood (Landgate, 2011) shows that water flowed through this sink across the AWRA catchment boundary over several days and proceeded through to the much larger and deeper lake system $50 \mathrm{~km}$ south. Topographically the AWRC and DEM-H are correct since filling either salt lake systems would cause the Yarra Yarra to continue to flow south into the Murchison River. Which is used depends on the application but is an important area for consideration given the numerous occurrences of distributaries and un-coordinated drainage networks across the continent.

It is unfortunate that AWRA boundaries are needed before analysis based on the 1 second DEM-H could be completed. ANUDEM has been revised many times for the SRTM project to accommodate the relatively new sources of dense noisy data. The program is in the process of major revision incorporating further enhancements to eliminate smoothing differences between neighbouring tiles. Similarly the stream networks used for guiding the interpolation are being progressively improved. Both will lead to an even better hydrological and terrain analysis resource.

\section{CONCLUSIONS}

In the same way that Hutchinson and Dowling (1991) found that there was a significant increase in resolvability moving from $1 / 40^{\text {th }}$ to $1 / 20^{\text {th }}$ degree DEMs, the increase in resolution from 9 to 1 second is a significant improvement in resolving catchments and stream networks.

While the 1 second SRTM provides a huge increase in detail and allows many deviations to be reconciled there are circumstances where issues remain: 
Dowling et al., Continental hydrologic assessment using the 1 second (30m) SRTM DEM of Australia.

- there are still some cases where the terrain is so subtle that even the SRTM-based DEMs cannot reliably resolve the correct boundaries

- the problems associated with inclusion of breakouts (distributaries) in either the upstream or downstream catchment still remain.

This study illustrates that basin definition, particularly in distributary landscapes, depends critically on accurate elevation data. The SRTM data provides a detailed quantitative resource to support continental definition of hydrological boundaries and networks.

While at this stage it is not practical to wait for complete analysis of the 1 second DEM-H before releasing the AWRA drainage divisions and river regions, users should be advised that a revision is likely in the near future based on DEM-H. Partial 1 second DEM-H analysis in areas of interest, as shown in the Yarra Yarra Creek example, has assisted in improved derivation of AWRA Regions boundaries.

\section{ACKNOWLEDGMENTS}

The development of the national 1 second SRTM-derived DEMs was funded by the Water for a Healthy Country Research Flagship and the Bureau of Meteorology, supported by Geoscience Australia and in collaboration with the Fenner School, ANU.

\section{REFERENCES}

AWRC (1965). Review of Australia's Water Resources 1963. Australian Water Resources Council, Dept National Development, Canberra, 107pp.

AWRC (1976). Review of Australia's Water Resources 1975. Australian Water Resources Council, Dept National Resources, Australian Government Publishing Service, Canberra, 170pp.

BoM (2010) Australian Hydrological Geospatial Project, Australian Bureau of Meteorology

BoM (2011a) Australian Water Resources Assessment. http://www.bom.gov.au/water/awra/index.shtml

BoM (2011b) Australian Hydrological Geospatial Hydrology Reporting Regions 1:250,000 scale 2011 (Beta), Commonwealth of Australia (Bureau of Meteorology)

Dowling, T.I., M.F. Hutchinson, A.M. Read and J.C. Gallant (in prep). Drainage enforcement of the 1 second SRTM DEM for Australia. To be submitted to Remote Sensing of Environment.

Gallant, J.C. (2011) An adaptive smoothing method for improving noisy DEMs. http://geomorphometry.org/Gallant2011

Gallant, J.C., A.M. Read, T.I. Dowling, and J.M. Austin (in prep) Removing Vegetation offsets from the 1 second SRTM DEM for Australia. To be submitted to Remote Sensing of Environment.

Geoscience Australia (2008) GEODATA 9 Second DEM of Australia Version 3, Canberra.

Geoscience Australia (2009) AusHydro 1:250,000, Version 1.6, Canberra.

Geoscience Australia and CSIRO Land \& Water (2011) 1 Second SRTM derived Digital Elevation Models User Guide. Version 1.0.4., Geoscience Australia, Canberra.

Hutchinson, M.F. (1989). A new procedure for gridding elevation and streamline data with automatic removal of spurious pits. Journal of Hydrology, 105, 211-232

Hutchinson, M.F. and T.I Dowling (1991). A continental hydrological assessment of a new grid-based Digital Elevation Model of Australia. Hydrological Processes, 5, 45-58.

Landgate (2011) Floodmap project, http://floodmap.landgate.wa.gov.au, Satellite Remote Sensing Services, Landgate, Leeuwin Centre for Earth Sensing Technologies, WA

Pilgrim, D.H. (1987). Ed. Australian Rainfall and Runoff, a Guide to Flood Estimation. Volume 1. Institution of Engineers, Australia. Canberra.

Read, A.M., J.C. Gallant and T.I. Dowling (in prep) Removing Stripes and Voids from the 1 second SRTM DEM for Australia. To be submitted to Remote Sensing of Environment.

Stein J.L., M.F. Hutchinson, and J.A. Stein (2011). National Catchment and Stream Environment Database version 1.1.1. National-catchment-databasev1.1.1-release-notes. Fenner School of Env. and Society, Australian National University, Canberra, ACT 0200, Australia.

Van de Graaff. W.J.E., R.W.A. Crowe, J.A. Bunting and M.J. Jackson (1977). Relict early Cainozoic drainages in arid Western Australia, Z. Geomorph. N. F. 21, 379-400.

Verdin, K.L. and J.P. Verdin (1999). A topological system for delineation and codification of the Earth's river basins. Journal of Hydrology 218(1), 1-12. 